\title{
Progressive myoclonic epilepsy type 7
}

INSERM

\section{Source}

INSERM. (1999). Orphanet: an online rare disease and orphan drug data base.

Progressive myoclonic epilepsy type 7. ORPHA:435438

A rare, genetic, neurological disorder characterized by childhood to adolescent onset of progressive myoclonus (which becomes very severe and results in major motor impediment) associated with infrequent tonic-clonic seizures, and, occasionally, ataxia. Learning disability prior to seizure onset and mild cognitive decline may be associated. 